\title{
SENSORIAMENTO REMOTO APLICADO À ANÁLISE TEMPORAL DA RELAÇÃO USO DA TERRA / TEMPERATURA E ALBEDO DE SUPERFÍCIE NA BACIA DO RIO VIEIRA NO NORTE DE MINAS GERAIS
}

\author{
LEITE, Reinaldo Leite - manoelreinaldo@ig.com.br \\ BRITO, Jorge Luís Silva - jbrito@ufu.br \\ Inst. Geografia - Lab. Cartografia e Sensoriamento / UFU - Univ. Fed. Uberlândia
}

\begin{abstract}
RESUMO. Este trabalho objetivou analisar, com auxílio de dados TM - Landsat 5, as relações entre as mudanças no uso da terra e a variação da temperatura e do albedo de superfície, no período sazonal de inverno da bacia do Rio Vieira para os anos de 1985, 1995 e 2010. Do ponto de vista operacional, o tempo de execução da metodologia aplicada ao mapeamento do uso da terra, desde a aquisição dos produtos orbitais até a validação dos mapeamentos, foi relativamente curto. Este fato que merece destaque, sobretudo, porque permitiu a elaboração de uma vasta gama de informações temporais da bacia do Rio Vieira, com destaque para a recuperação de $54,79 \mathrm{~km}^{2}$ de vegetação natural em 25 anos. Do ponto de vista do mapeamento termal, o coeficiente de variação apontou uma correlação entre os dados de temperatura obtidos pelo modelo SEBAL e os dados de temperatura do ar, medidos a aproximadamente $1,5 \mathrm{~m}$ do solo, variando de 0,61 e $11,38 \%$ e uma correlação geral em $r^{2}=0,961$.
\end{abstract}

Palavras-chave: Sensoriamento remoto, uso da terra, SEBAL e Bacia do Rio Vieira.

REMOTE SENSING APPLIED TO TEMPORAL ANALYSIS OF THE RELATIONSHIP OF THE LAND USE / TEMPERATURE AND ALBEDO OF SURFACE IN BASIN RIVER VIEIRA IN NORTE DE MINAS GERAIS

\begin{abstract}
This study aimed to analyze with the help of TM data - Landsat 5, the relationship between the changes in land use and the variation of temperature and surface albedo, during period winter in basin River Vieira for the years 1985, 1995 and 2010. From an operational standpoint, the runtime of the methodology applied to the mapping of land use, since the acquisition of orbital products to validate the mappings, was relatively short. A fact that deserves attention, especially because it led to the development of a wide range of temporal information of Vieira River basin. With emphasis on the recovery of $54.79 \mathrm{~km}{ }^{2}$ of natural vegetation in 25 years. From the viewpoint of the thermal mapping, the coefficient of variation showed a correlation between the temperature obtained by the SEBAL model and the air temperature, measured at about $1.5 \mathrm{~m}$ high, ranging from 0.61 to $11.38 \%$ and an overall accuracy $r^{2}=0.961$.
\end{abstract}

Keywords: Remote sensing, Land use, River Basin Vieira and SEBAL.

TELEDETECCIÓN APLICADA A LA ANÁLISIS TEMPORAL DE LA RELACION USO DE LA TIERRA / TEMPERATURA Y ALBEDO DE LA SUPERFÍCIE EN LA CUENCA DEL RÍO VIEIRA EM EL NORTE DE MINAS GERAIS

RESUMEN. Este estudio tuvo como objetivo analizar con la ayuda de los datos TM - Landsat 5, la relación entre los cambios en el uso del suelo y la variación de la temperatura y el albedo de la superficie, durante la temporada de invierno del cuenca del río Vieira para los años 1985, 1995 y 2010 . Desde un punto de vista operativo, el tiempo de ejecución de la metodología aplicada a la cartografía de uso de la tierra, desde la adquisición de productos de orbitales para validar las asignaciones, fue relativamente corto. Un hecho que merece atención, sobre todo porque llevó al desarrollo de una amplia gama de información temporal Vieira cuenca del río. Con énfasis en la recuperación de 54,79km² de la vegetación natural en 25 años. Desde el punto de vista de la cartografía térmica, el coeficiente de variación mostró una correlación entre los datos de temperatura obtenidos por el modelo y los datos de la temperatura del aire SEBAL, mide aproximadamente 1,5 m de altura, que van desde 0,61 hasta 11,38 \% y una correlación global de $r^{2}=0,961$.

Palabras clave: teledetección, el uso del suelo, y la Cuenca del Río SEBAL Vieira. 


\section{INTRODUÇÃO}

Os estudos sobre o "uso da terra" devem contemplar as variações no espaço-tempo por força das mudanças de orientações que norteiam a utilização dos espaços em diferentes momentos. Isso é, a dinâmica imposta pelos ciclos econômicos sobre o uso das terras impõe uma variação nestes ambientes ao longo do tempo, com consequências para o espaço físico, ou seja, áreas que em determinados períodos eram destinadas à produção podem ser, em outros períodos, abandonadas, de forma que o contrário também pode ser verdadeiro. Dentro dessa lógica, as florestas, os sistemas agroflorestais e os solos podem funcionar tanto como reserva ou fontes de carbono.

Fato é que, em 1990, o primeiro relatório do Intergovernmental Panel on Climate Change IPCC - denunciava que as concentrações dos gases estufas como o dióxido de carbono $\left(\mathrm{CO}_{2}\right)$, o metano $\left(\mathrm{CH}_{4}\right)$ e o óxido nitroso $\left(\mathrm{N}_{2} \mathrm{O}\right)$ aumentaram cerca de $30 \%$, $145 \%$ e $15 \%$ respectivamente, desde a revolução industrial do século XVIII até o ano de 1992 . Essa realidade conduziria o clima da Terra a mudanças que trariam consequências negativas para 0 sistema natural e humano.

Dentre os responsáveis pelas alterações do clima terrestre destacam-se a queima de combustíveis fósseis e o chamado forçamento radioativo (EFEITO, 1999). O forçamento radioativo nada mais é do que uma perturbação no balanço de energia do sistema Terraatmosfera, ou seja, as alterações dos constituintes da superfície terrestre implicam também em alterações no equilíbrio e distribuição do balanço de energia à superfície.

De maneira que os desmatamentos significam maior emissão de $\mathrm{CO}_{2}$ para a atmosfera, além de possibilitarem maior ressecamento do solo e aumento de temperatura de superfície. As alterações do "uso da terra", a exemplo de pastagens e do uso agrícola, significam alterações no conteúdo de carbono do solo. As florestas plantadas contribuem para a remoção e emissão de $\mathrm{CO}_{2}$ para a atmosfera. (EFEITO, 1999)

Essas alterações nos revestimentos naturais do solo e o uso da terra impõem uma nova busca pelo equilíbrio da distribuição dos componentes do balanço de radiação na superfície e na atmosfera, resultando em alterações como o chamado "efeito estufa" antrópico.

Nesse caso, a temperatura dos diferentes sistemas de uso da terra será diretamente proporcional à quantidade de energia térmica associada. Como exemplo, pode-se citar o fato de que, em uma área cuja radiação solar pode ser considerada constante, as variações de temperatura e do albedo de superfície ocorrerão em função do tipo de cobertura da terra. Tendo em vista que um sistema de uso florestal consumirá mais energia térmica do que um sistema de uso com solo em exposição e assim por diante.

Essa realidade, quando considerada à luz das concepções da termodinâmica, implica que o ambiente alterado, ainda que seja uma pequena porção em área, tende a restabelecer o equilíbrio térmico com os seus sistemas vizinhos, ou seja, haverá transferência de energia e consequentemente variação na temperatura e no albedo de superfície ao longo do tempo e do espaço.

Diante desta realidade, o sensoriamento remoto se destaca como uma ferramenta de importância singular, já que os dados de sensor remoto vêm dando suporte a vários estudos sobre a superfície da Terra, sobretudo quando se considera a possibilidade de obtenção de informações temporais como os dados da série TM - Landsat 5, que se pontuam como uma importante fonte de informações históricas, permitindo o mapeamento e a quantificação de informações pretéritas e atuais das áreas imageadas.

Assim sendo, este trabalho procurou analisar, com auxílio de dados TM - Landsat 5, as relações entre as mudanças no uso da terra e a variação da temperatura e do albedo de superfície no período sazonal de inverno da bacia do Rio Vieira nos últimos 25 anos.

A escolha da bacia do Rio Vieira se justifica pelo fato de que esta área foi palco de um rápido e intenso crescimento populacional. De forma que essa realidade proporcionou várias modificações nos sistemas de uso da terra desta bacia, como por exemplo: rápida expansão urbana, recuperação de áreas antropizadas e a antropização de áreas naturais. Permitindo, neste contexto, o desenvolvimento deste trabalho num ambiente com as devidas alterações dos sistemas de uso da terra.

Dentro desta perspectiva, analisar a dinâmica do campo térmico da bacia do Rio Vieira, a partir da série histórica do TM - Landsat 5 é de singular relevância para a compreensão dos impactos ambientais acarretados pelas intervenções humanas neste ambiente. 


\section{LOCALIZAÇÃO DA ÁREA DE APLICAÇÃo}

A bacia do Rio Vieira está localizada no Norte do estado de Minas Gerais, totalmente inserida dentro dos limites do município de Montes Claros, como ilustra a Figura 01, ocupando uma área de $578,31 \mathrm{~km}^{2}$, a qual equivale a $16,20 \%$ das terras do município, locadas, especificamente, no polígono formado pelas coordenadas $16^{\circ} 32^{\prime} 53^{\prime \prime}$ e $16^{\circ} 51^{\prime} 26^{\prime \prime}$ de latitude $S$ e $43^{\circ} 44^{\prime} 05^{\prime \prime}$ e $44^{\circ} 03^{\prime} 40^{\prime \prime}$ de longitude W.

O perímetro urbano do município de Montes Claros ocupa 15,80\% da área da bacia, o qual, conforme destacam os dados do censo de 2010 do IBGE, abriga uma população de 344.479 habitantes, apontando uma densidade demográfica de 3770,57 hab/km² (IBGE, 2011).

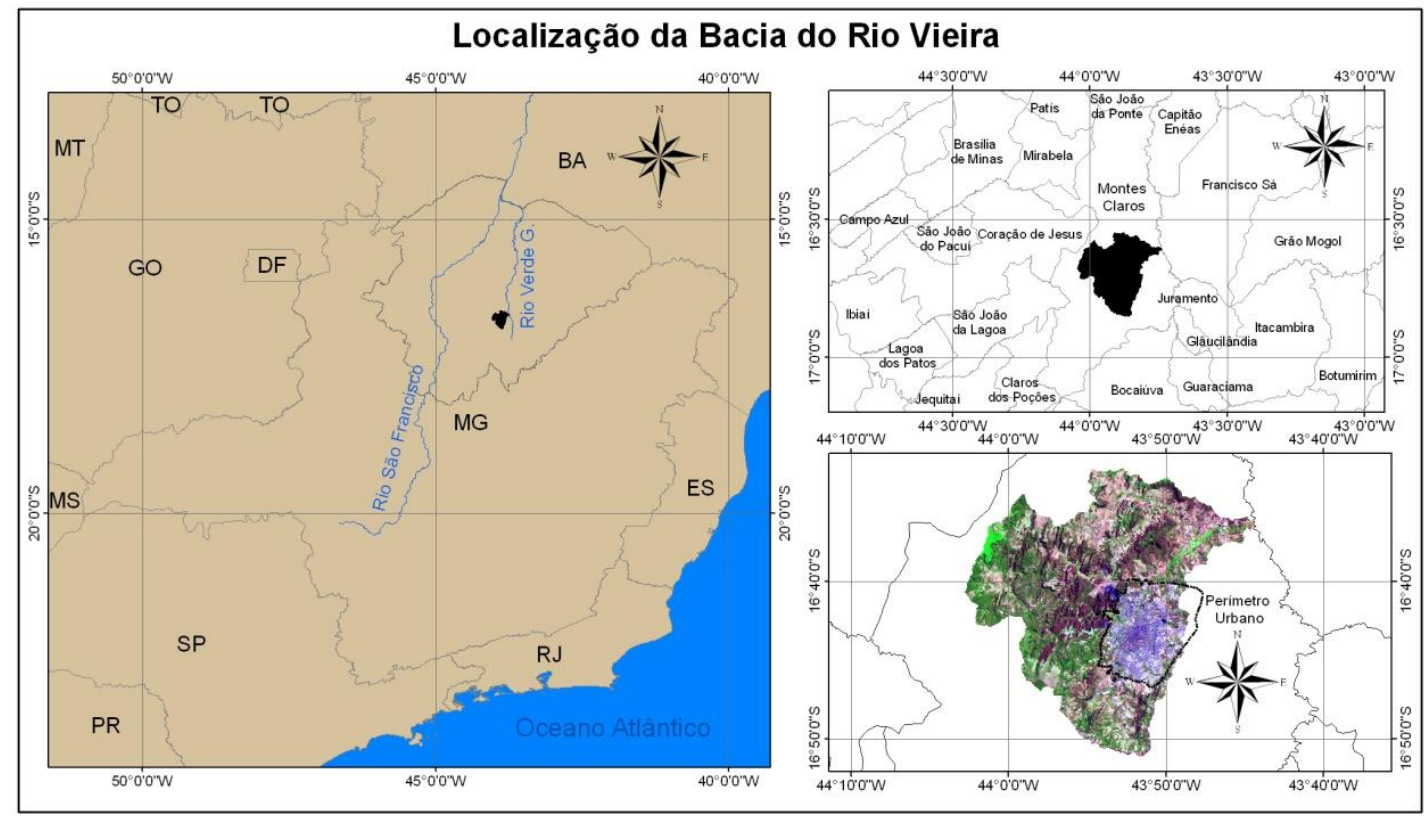

Figura 01 - Localização da Bacia do Rio Vieira.

\section{MATERIAIS E PROCEDIMENTOS TÉCNICOS OPERACIONAIS}

Para a realização deste trabalho os seguintes materiais foram necessários:

- Imagens do satélite Landsat 5, sensor Thematic Mapper (TM), órbita ponto 218 / 72, no formato digital de 28/08/1985, 09/09/1995 e 17/08/2010.

- Imagens semicontroladas do modelo numérico de elevação oriundo do subsistema VNIR/ASTER, com resolução espacial de $30 \mathrm{~m}$, disponibilizadas no Site da NASA(http://asterweb.jpl.nasa.gov/gdem-wist.asp)

- Dados climatológicos das estações de controle do Centro de Previsão de Tempo e Estudos Climatológicos (CPTEC), da Universidade Estadual de Montes Claros, da Universidade Federal de Minas Gerais/campus de Montes Claros. E das estações de Montes Claros, Diamantina e Itamarandiba, de responsabilidade do Instituto Nacional de Meteorologia (INMET), e da estação do aeroporto de Montes Claros, para as datas e horários correspondentes à passagem do sensor. 


\subsection{Processamento das Imagens para uso da Terra}

Disponibilizadas pelo Instituto Nacional de Pesquisas Espaciais, as imagens TM-Landsat 5 possuem nível básico de tratamento. Neste caso, houve a necessidade de correção e tratamento dessas imagens. As etapas executadas

Contemplaram os seguintes passos: correção atmosférica, correção geométrica e correção topográfica.

O modelo de correção atmosférica utilizado foi o desenvolvido por Chavez (1988). Para tanto foram computados os valores estatísticos de cada banda espectral das imagens TM Landsat 5 no intuito de montar a tabela 01 , a qual contém os valores escuros, de cada banda, para serem subtraídos.

\section{Tabela 01}

Níveis digitais escuros de referência para correção atmosférica

\begin{tabular}{|c|c|c|c|c|c|}
\hline Banda & ND & Banda & ND & Banda & ND \\
\hline \multicolumn{2}{|c|}{2010} & \multicolumn{2}{|c|}{1995} & \multicolumn{2}{|c|}{1985} \\
\hline B1 & 35 & B1 & 37 & B1 & 58 \\
\hline B2 & 15 & B2 & 12 & B2 & 31 \\
\hline B3 & 13 & B3 & 10 & B3 & 20 \\
\hline B4 & 5 & B4 & 4 & B4 & 15 \\
\hline B5 & 3 & B5 & 3 & B5 & 6 \\
\hline B7 & 0 & B7 & 1 & B7 & 0 \\
\hline
\end{tabular}

Posteriormente foi montada a equação 01, para a subtração dos valores de referencia em cada banda:

DkSB $=([$ B_referência $]-$ Float(valor_escuro $))$

01

O resultado desta expressão é uma imagem cujos valores de radiância de percurso foram suavizados, sobretudo para os alvos em que a nível do satélite não deveriam registrar valores de energia.

No passo seguinte, as imagens foram registradas ao MNT através da extensão do ArcGis 9.3.1 (ArcToolbox > Create Ortho Corrected). Para tanto, foram criados os arquivos de Raster Dataset associados a 25 pontos de controle para cada imagem e coincidentes com 0 MNT/ASTER. Esse procedimento apresentou um erro quadrático médio de $8,45 \mathrm{~m}$, ou seja, menor do que $1 / 2$ pixel.

A necessidade de realizar a correção topográfica nas imagens advém do fato de que áreas sombreadas pelo relevo, após a correção atmosférica realizada anteriormente, apresentarem valores na ordem de zero. A execução dos cálculos para a correção topográfica implica na transformação dos níveis digitais das imagens, corrigidas na etapa anterior, em dados físicos de reflectância $(\lambda)$.

Para esta conversão utilizou-se da equação 02 apresentada por Markham e Barker (1986), a qual converte os (NDs) de cada uma das bandas do TM Landsat 5 em radiância espectral monocromática, que representa a energia solar refletida e a energia emitida pela superfície da 
Terra, de cada pixel, por unidade de tempo, de área, de ângulo sólido e de comprimento de onda medido ao nível do satélite.

$\mathrm{L}_{\lambda \mathrm{i}}=a_{i}+\frac{b_{i}-a_{i}}{255} \times N D$

Em que, a e b são radiâncias espectrais mínimas e máximas $\left(\mathrm{Wm}^{-2} \mathrm{sr}^{-1} \mu \mathrm{m}^{-1}\right)$, conforme tabela 02 e 03; ND são os níveis digitais de cada pixel da imagem variando de 0 a 255; e i são as bandas $(1,2,3,4,5,6$ e 7$)$ do satélite TM Landsat 5 .

Para a obtenção da reflectância, que é a razão entre o fluxo de radiação solar refletido pela superfície e o fluxo de radiação global incidente, utilizou-se a equação (03) apresentada por Allen et. al. (2002).

$$
\rho_{\lambda i}=\frac{\pi \cdot L_{\lambda i}}{k_{\lambda i} \cdot \cos Z \cdot d_{r}}
$$

Em que, $L_{\lambda i}$ é a radiância espectral monocromática de cada banda do TM Landast $5, k_{\lambda i}$ é a irradiância espectral solar no topo da atmosfera de cada banda (tabela 02 e 03), Z é o anglo zenital solar e pode ser obtido com o auxílio de MNT e a equação (05), proposta por Duffie e Beckman (1991), e d $d_{r}$ é o inverso do quadrado da distância relativa Terra-Sol em unidades astronômicas de acordo com o dia do ano.

Para a estimativa de $d_{r}$ se considera a equação (04) apresentada por Duffie e Beckman (1980).

$d_{r}=1+0,033 \cos (2 \pi$ DDA / 365)

Sendo que DDA é o dia do ano contado consecutivamente de 01 de janeiro até a data de passagem do sensor, considerando fevereiro com 28 dias.

$\cos Z=\operatorname{sen}(\delta) \operatorname{sen}(\varphi) \cos (s) \operatorname{sen}(\delta) \cos (\varphi) \operatorname{sen}(s) \cos (Y)+\cos (\delta) \cos (\varphi) \cos (s) \cos (\omega)+\cos (\delta) \operatorname{sen}(\varphi) s$ en $(s) \cos (\gamma) \cos (\omega)+\cos (\delta) \operatorname{sen}(\gamma) \operatorname{sen}(s) \operatorname{sen}(\omega)$

Sendo que $\delta=$ declinação do Sol; $\varphi=$ latitude do pixel (positiva no hemisfério Norte e negativa no hemisfério Sul); $s=$ inclinação da superfície, onde $s=0$ para superfície horizontal e $s=n / 2$ rad para inclinação vertical, $Y=$ ângulo do aspecto da superfície, onde $Y=0$ para inclinação orientada para sul, $Y=-\Pi / 2$ rad para inclinação orientada para leste, $Y=+\Pi / 2 \mathrm{rad}$ para inclinação voltada para oeste $\mathrm{e} Y= \pm \Pi$ rad para inclinações orientadas para norte.

O parâmetro $\omega$ é o ângulo horário, com $\omega=0$ ao meio-dia solar, $\omega<0$ pela manhã e positivo à tarde. 


\section{Tabela 02}

Mapeador Temático (TM) Landsat 5: descrição, intervalo de comprimentos de onda e coeficientes de calibração, radiâncias espectrais mínima (a) e máxima (b) e irradiância espectral no topo da atmosfera para imagens até 04/05/2003

\begin{tabular}{|c|c|c|c|c|}
\hline \multirow[t]{2}{*}{ Descrição dos canais } & \multirow[t]{2}{*}{$\begin{array}{c}\text { Comprimento } \\
\text { de onda } \\
(\mu \mathrm{m})\end{array}$} & \multicolumn{2}{|c|}{$\begin{array}{l}\text { Coeficiente de } \\
\text { calibração } \\
\left(\mathrm{Wm}^{-2} \mathrm{sr}^{-1} \mu \mathrm{m}^{-1}\right)\end{array}$} & \multirow[t]{2}{*}{$\begin{array}{l}\text { Constante solar } \\
\qquad\left(\mathbf{W m}^{-2} \boldsymbol{\mu m}^{-1}\right)\end{array}$} \\
\hline & & $\mathbf{a}$ & $\mathbf{b}$ & \\
\hline B 1 (azul) & $0,45-0,52$ & $-1,52$ & 152,0 & 1958,00 \\
\hline B 2 (verde) & $0,53-0,61$ & $-2,84$ & 296,81 & 1828,00 \\
\hline Banda 3 (vermelho) & $0,62-0,69$ & $-1,17$ & 204,3 & 1559,00 \\
\hline B 4 (infrav. próximo) & $0,78-0,90$ & $-1,51$ & 206,2 & 1045,00 \\
\hline B 5 (infrav. médio) & $1,57-1,78$ & $-0,37$ & 27,19 & 219,00 \\
\hline B 6 (infrav. termal) & $10,4-12,5$ & 1,2378 & 15,303 & - \\
\hline B 7 (infrav. médio) & $2,10-2,35$ & $-0,15$ & 14,38 & 75,00 \\
\hline
\end{tabular}

Fonte: Serviço Geológico dos Estados Unidos da América.

\section{Tabela 03}

Mapeador Temático (TM) Landsat 5: descrição, intervalo de comprimentos de onda e coeficientes de calibração, radiâncias espectrais mínima (a) e máxima (b) e irradiância espectral no topo da atmosfera para imagens pós 04/05/2003

\begin{tabular}{|c|c|c|c|c|}
\hline \multirow[t]{2}{*}{$\begin{array}{l}\text { Descrição dos } \\
\text { canais }\end{array}$} & \multirow[t]{2}{*}{$\begin{array}{l}\text { Comprimento } \\
\text { de onda }(\mu \mathrm{m})\end{array}$} & \multicolumn{2}{|c|}{$\begin{array}{c}\text { Coeficiente de } \\
\text { calibração } \\
\left(\mathbf{W m}^{-2} \mathrm{sr}^{-1} \mu^{-1}\right)\end{array}$} & \multirow[t]{2}{*}{$\begin{array}{c}\text { Constante solar } \\
\left(\mathrm{Wm}^{-2} \boldsymbol{\mu m}^{-1}\right)\end{array}$} \\
\hline & & $\mathbf{a}$ & $\mathbf{b}$ & \\
\hline B 1 (azul) & $0,45-0,52$ & $-1,52$ & 193,0 & 1957,00 \\
\hline B 2 (verde) & $0,53-0,61$ & $-2,84$ & 365,0 & 1826,00 \\
\hline B 3 (vermelho) & $0,62-0,69$ & $-1,17$ & 264,0 & 1554,00 \\
\hline B 4 (infrav. próximo) & $0,78-0,90$ & $-1,51$ & 221,0 & 1036,00 \\
\hline B 5 (infrav. médio & $1,57-1,78$ & $-0,37$ & 30,2 & 215,00 \\
\hline B 6 (infrav. termal) & $10,4-12,5$ & 1,2378 & 15,303 & - \\
\hline B 7 (infrav. médio) & $2,10-2,35$ & $-0,15$ & 16,5 & 80,67 \\
\hline
\end{tabular}

Fonte: Serviço Geológico dos Estados Unidos da América

Para os cálculos de correção do efeito topográfico, nas imagens deste trabalho, considerou-se o fato de que a superfície reflete a radiação de uma forma isotrópica, em conformidade com o 
modelo de reflectância Lambertiano. Nesse modelo, as variações na reflectância são devidas à quantidade da radiação incidente, já que a iluminação de uma superfície é diretamente proporcional à intensidade luminosa da fonte na direção da superfície, portanto, proporcional ao cosseno do ângulo de incidência dos raios luminosos. Nesse caso, dada a normalidade da incidência da radiação, o recebimento de energia sofrerá a mesma variação que o cosseno do ângulo zenital, Smith et al. (1980).

Do ponto de vista operacional, foram considerados os cossenos de cos (e) e o cos (i) para a correção do efeito topográfico, de forma que o $\cos (i)$ representa o ângulo entre a fonte de energia e a normal a superfície e foi obtido de acordo com a expressão (06) enquanto o cos (e) representa o ângulo entre a fonte e a inclinação do terreno e foi obtido através da expressão (07), implementadas através do operador matemático do ArcGis 9.3.1.

Cos_ $\mathrm{i}=\operatorname{Cos}(($ Float $(n / 180) *$ Float $(90-45.5278))$ IF(SLOP"METERS" $==0.0) \operatorname{OrCos}($ Float $(n / 180) *$ Float $(90-45.5$

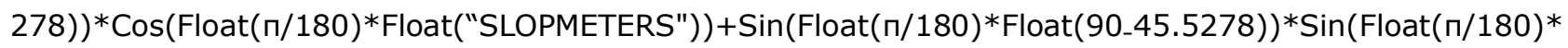
Float("SLOPMETERS"))*Cos(Float(n/180)*Float(48.1072)-Float(ASPECT))

(06)

Sendo que $п$ é uma constante, considerada aqui até sua trigésima primeira decimal, 45.5278 era a elevação do Sol no momento da passagem do sensor pela área de estudo, "SLOPMETERS" é a declividade do terreno obtida em graus, 48.1072 era o azimute solar no momento da passagem do sensor e ASPECT é o azimute do terreno.

Já o $\operatorname{Cos}(e)$ foi obtido pela expressão (12):

Cos_e $=\operatorname{Cos}($ Float $(" S L O P M E T E R S ") ~ *$ Float $(n / 180))$

Por fim, as imagens foram normalizadas topograficamente, como explicita a Figura (02), a partir da expressão (08):

NTP $=\operatorname{IF}($ cos_i $<=0.0) \operatorname{Or}\left(\left([\text { Banda_Corr }]^{*} \cos \_e\right) /\left(\cos \_i * \cos \_e\right)\right)$

Sendo IF e Or funções booleanas do operador, [Banda_corr], cada banda da imagem que foi submetida à normalização.

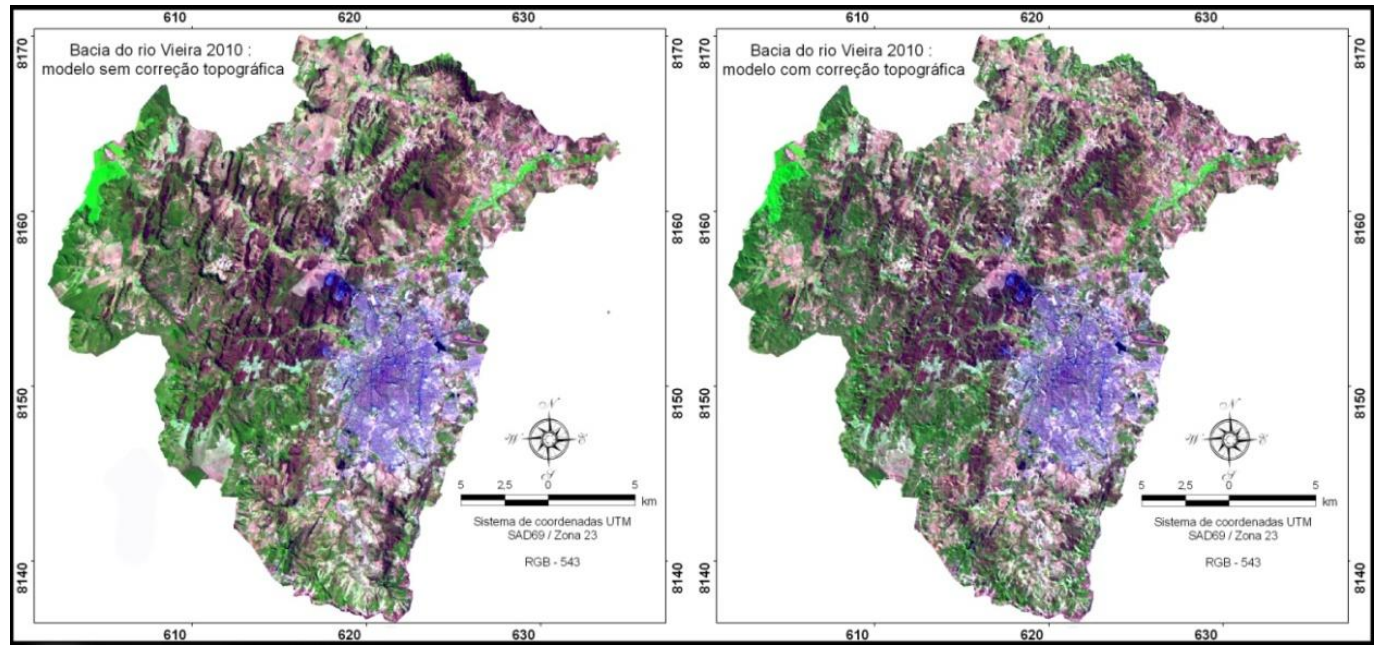

Figura 02 - modelos sem e com correção topográfica

Ano 8 - Vol. 10 - JAN/JUN 2012 
No passo seguinte, posterior aos tratamentos supramencionados, foram montados os elementos para iniciar a classificação do Uso da Terra. Dentre estes elementos destaca-se o (NDVI) que é o resultado da razão entre a diferença da banda do infravermelho próximo (banda $4=\rho_{4}$ ) e a do vermelho (banda $3=\rho_{3}$ ), normalizado pela soma das mesmas, de forma que pode ser expressa pela equação (09).

$$
N D V I=\frac{\rho_{4}-\rho_{3}}{\rho_{4}+\rho_{3}}
$$

Os valores de (NDVI) variam de -1 a 1 e é um indicativo das condições de densidade, porte e saúde da vegetação. Os valores próximos de 0 indicam superfície com pouca vegetação; os valores próximos de 1 indicam superfícies vegetadas a densamente vegetadas. Já os valores menores que 0 indicam a presença de água ou nuvens na cena.

A transformação Tasseled Cap também foi um importante componente para a classificação, nesta transformação seis bandas do sensor TM são sintetizadas em três novas componentes a componente brightness, que é a soma ponderada de todas as bandas e está relacionada à variação espectral dos solos; a componente greenness está relacionada ao vigor da vegetação e é a diferença entre o canal do infravermelho próximo e os demais; a componente wetness, que é o contraste entre o infravermelho médio e os demais canais (GLERIANI et al., 2003). Cada componente foi obtida a partir das equações 10,11 e 12 .

$\mathrm{BR}$

$0,3037 * \operatorname{tm} 1+0,2793 * \operatorname{tm} 2+0,4743 * \operatorname{tm} 3+0,5585 * \operatorname{tm} 4+0,5082 * \operatorname{tm} 5+0,1863 * \operatorname{tm} 7$

$\mathrm{GR}=-0,2848 * \operatorname{tm} 1-0,2435 * \operatorname{tm} 2-0,5436 * \operatorname{tm} 3+0,7243 * \operatorname{tm} 4+0,0840 * \operatorname{tm} 5-0,1800 * \operatorname{tm} 7$

WT $=$

$0,7112 * \operatorname{tm} 5+0,4572 * \operatorname{tm} 7$
$0,1509 * \operatorname{tm} 1+0,1973 * \operatorname{tm} 2+0,3279 * \operatorname{tm} 3+0,3406 * \operatorname{tm} 4-$ (12)

$\mathrm{Na}$ etapa seguinte foram definidas as classes de uso da terra a serem mapeadas. A elaboração desta legenda obedeceu ao esquema teórico apresentado por Heymann (1994), conforme Figura 03.

No que diz respeito à classificação, o método foi o supervisionado e o algoritmo classificador foi o de árvore de decisão. Este é um tipo de classificador de múltiplos estágios que pode utilizar uma pilha de imagens independentes do sistema de projeção (ENVI 2010). As regras de árvore de decisão permitem classificar as imagens utilizando dados temporais, além de derivadas de MNT.

Assim, para os mapeamentos realizados para os anos de 1985, 1995 e 2010, foram utilizados tasseled cap de inverno, NDVI de inverno, as bandas 3, 4, 5 e 7 das imagens de inverno e 0 MNT, totalizando 10 componentes para a classificação. 


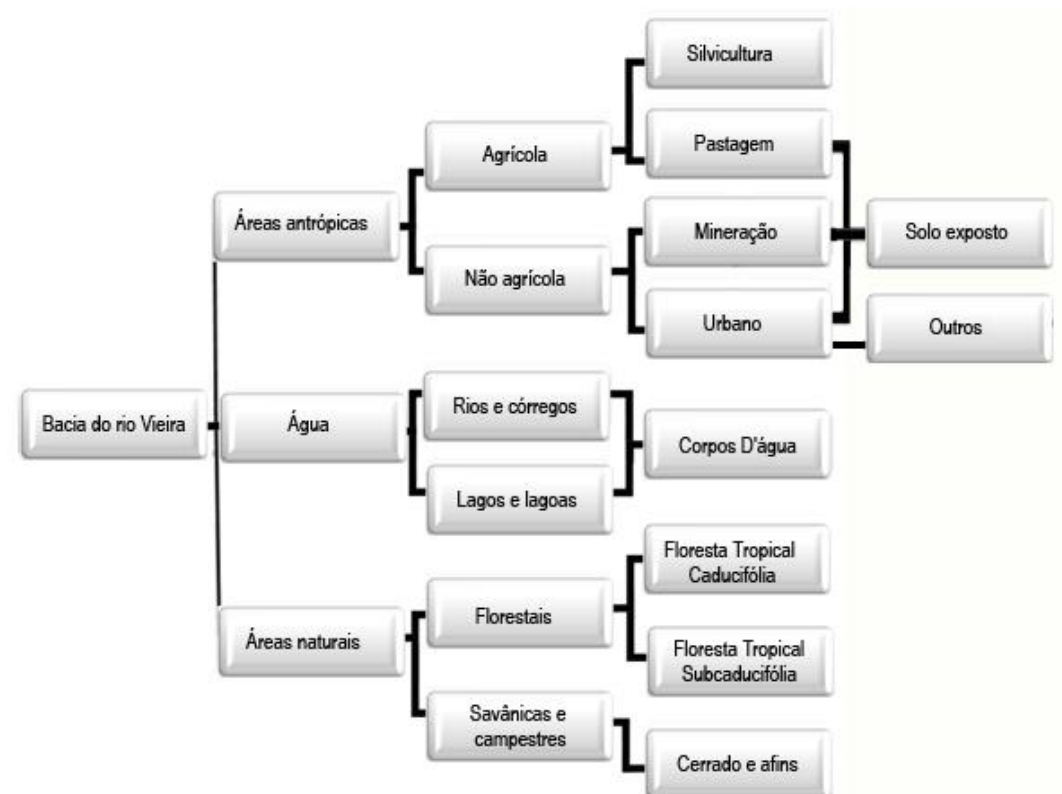

Figura 03 - hierarquização de legenda para mapeamento do uso da terra.

Posterior à classificação de Uso da Terra, seguiram-se os procedimentos para a validação dos mapeamentos. Os instrumentos para a validação dos mapeamentos foram fornecidos pela matriz de confusão como a acuracidade geral e índice Kappa.

A matriz foi elaborada com auxílio de produtos cartográficos externos e a partir da análise de amostras de conjuntos de pixels distribuídos pelos sistemas de uso da terra de cada ano mapeado. Para o ano de 1985, setenta e três pontos amostrais foram colhidos, para o ano de 1995, oitenta e quatro pontos de amostras foram testados, e para o ano de 2010, oitenta e dois pontos amostrais foram checados.

Posteriormente a elaboração da matriz utilizou-se a equação 13 para se obter o coeficiente Kappa, tendo em vista que ele pode revelar uma melhor estimativa sobre a acuracidade de um determinado mapeamento, tendo em vista que nos cálculos deste coeficiente são considerados todos os componentes da matriz.

$$
K=\frac{x \sum_{i=1}^{r} x_{i i}-\sum_{i=1}^{r} x_{i+} x_{+i}}{x^{2}-\sum_{i=1}^{r} x_{i+} x_{+i}}
$$

Sendo que $X$ são elementos da matriz de confusão; $r$, o número de categorias presentes na matriz de confusão; Xii são os elementos da diagonal principal; Xi+ é total da linha para uma dada categoria informacional; e $\mathrm{X}+\mathrm{i}$ é total da coluna para uma dada categoria informacional. 


\section{Tabela 04}

Matriz de confusão do mapeamento do ano de 1985.

\begin{tabular}{|c|c|c|c|c|c|c|c|c|c|c|}
\hline \multirow[b]{2}{*}{ Classes } & \multirow[b]{2}{*}{ Cerrado } & \multirow[b]{2}{*}{ FTC } & \multirow[b]{2}{*}{ FTS } & \multirow[b]{2}{*}{ Pastagem } & \multicolumn{6}{|c|}{ Solo } \\
\hline & & & & & Mineração & Urbano & exposto & Água & Outros & Total \\
\hline Cerrado & 38 & & 2 & & & & & & & 40 \\
\hline FTC & & 37 & & 3 & & 4 & & & & 44 \\
\hline FTS & 3 & & 22 & & & & & & & 25 \\
\hline Pastagem & & 1 & & 153 & & & 7 & & 4 & 165 \\
\hline Mineração & & & & & 16 & 6 & & 3 & & 25 \\
\hline Urbano & & 3 & & 2 & 2 & 161 & & & 2 & 170 \\
\hline \multicolumn{11}{|l|}{ Solo } \\
\hline exposto & & & & & & & 89 & & 1 & 90 \\
\hline Água & & & & & 3 & & & 12 & & 15 \\
\hline Outros & 5 & 2 & & 15 & 2 & & 2 & & 14 & 40 \\
\hline Total & 46 & 43 & 24 & 173 & 23 & 171 & 98 & 15 & 21 & 614 \\
\hline
\end{tabular}

Tabela 05

Matriz de confusão do mapeamento do ano de 1995.

\begin{tabular}{|c|c|c|c|c|c|c|c|c|c|c|c|}
\hline \multirow[b]{2}{*}{ Classes } & \multirow[b]{2}{*}{ Cerrado } & \multirow[b]{2}{*}{ FTC } & \multirow[b]{2}{*}{ FTS } & \multirow[b]{2}{*}{ Pastagem } & \multirow[b]{2}{*}{ Eucalipto } & \multicolumn{6}{|c|}{ Solo } \\
\hline & & & & & & Mineração & Urbano & exposto & Água & Outros & Total \\
\hline Cerrado & 39 & & 1 & & 1 & & & & & & 41 \\
\hline FTC & & 40 & & 2 & & & 18 & & & & 60 \\
\hline FTS & 3 & & 20 & & 13 & & & & & & 36 \\
\hline Pastagem & & & & 155 & & & & 12 & & 6 & 173 \\
\hline Eucalipto & & & 3 & & 142 & & & & & & 145 \\
\hline Mineração & & & & & & 18 & 3 & & 5 & & 26 \\
\hline Urbano & & 1 & & 1 & & 2 & 155 & & 1 & & 160 \\
\hline \multicolumn{12}{|l|}{ Solo } \\
\hline exposto & & & & & & & & 80 & & 4 & 84 \\
\hline Água & & & & & & 3 & & & 14 & & 17 \\
\hline Outros & 4 & 3 & & 17 & & & & 4 & & 20 & 48 \\
\hline Total & 46 & 44 & 24 & 175 & 156 & 23 & 176 & 96 & 20 & 30 & 790 \\
\hline
\end{tabular}

Acuracidade geral $=86,45 \%$; Coeficiente Kappa $=0.8404$ 


\section{Tabela 06}

Matriz de confusão do mapeamento do ano de 2010.

\begin{tabular}{|c|c|c|c|c|c|c|c|c|c|c|c|}
\hline Classes & Cerrado & FTC & FTS & Pastagem & Eucalipto & Mineração & Urbano & $\begin{array}{c}\text { Solo } \\
\text { exposto }\end{array}$ & Água & Outros & Total \\
\hline Cerrado & 40 & & 2 & & & & & & & & 42 \\
\hline FTC & & 45 & & 2 & & & 4 & & & & 51 \\
\hline FTS & 2 & & 22 & & 16 & & & & & 1 & 41 \\
\hline Pastagem & & & & 153 & & & & 3 & & 3 & 159 \\
\hline Eucalipto & & & 2 & & 140 & & & & & & 142 \\
\hline Mineração & & & & & & 15 & 4 & & 4 & & 23 \\
\hline Urbano & & 2 & & & & 2 & 159 & & 2 & 2 & 167 \\
\hline Solo & & & & & & & & & & & \\
\hline exposto & & & & & & & & 89 & & 1 & 90 \\
\hline Água & & & & & & 4 & & & 12 & & 16 \\
\hline Outros & 7 & 1 & & 18 & & & & 7 & & 21 & 54 \\
\hline Total & 49 & 48 & 26 & 173 & 156 & 21 & 167 & 99 & 18 & 28 & 785 \\
\hline
\end{tabular}

Acuracidade Geral $=88,66 \%$; Coeficiente Kappa $=0.8457$

\subsection{Processamento das imagens para obtenção do albedo e temperatura de superfície.}

O foco deste procedimento foi a obtenção dos mapas de temperatura e albedo de superfície, para tanto, cinco etapas foram executadas.

Na primeira etapa foi obtido o albedo planetário corresponde ao poder de reflexão da superfície mais a atmosfera e seus componentes para os comprimentos de onda curta $(0,3-3,0 \mu \mathrm{m})$. Sua obtenção se dá através do ajuste linear das reflectâncias espectrais, obtidas anteriormente pelas equações 02 e $03, \rho_{\lambda}$ com pesos $\omega_{\lambda}$ através da equação (14).

$a_{\text {toa }}=\left(\omega \rho_{\lambda, 1}\right)+\left(\omega \rho_{\lambda, 2}\right)+\left(\omega \rho_{\lambda, 3}\right)+\left(\omega \rho_{\lambda, 4}\right)+\left(\omega \rho_{\lambda, 5}\right)+\left(\omega \rho_{\lambda, 7}\right)$

Sendo que cada peso $\left(\omega_{1}, \omega_{2} \ldots \omega_{7}\right)$ pode ser obtido pela razão entre a constante solar de cada banda (Tabelas 02 e 03) e o somatório de todas as constantes $\Sigma E S U N$. Através da equação (15).

$$
\varpi_{\lambda, b}=\frac{E S U N_{\lambda, b}}{\sum E S U N_{\lambda, b}}
$$

$\mathrm{Na}$ segunda etapa foi computado o valor do Albedo corrigido, o qual representa o poder refletor da superfície ou albedo de superfície. O mesmo pode ser entendido como o coeficiente de reflexão da superfície para a radiação de onda curta, corrigidos os efeitos atmosféricos. 
Trata-se de uma medida adimensional que pode ser avaliada pela razão entre a radiação direta e a difusa em função do ângulo zenital solar.

A obtenção do albedo de superfície se deu por meio da equação (16), conforme recomendação de Allen et. al. (2002).

$$
\alpha=\frac{\alpha_{\text {toa }}-\alpha_{p}}{\tau_{s w}^{2}}
$$

Sendo que, $a_{\text {toa }}$ é o albedo planetário e $a_{p}$ é a radiação solar refletida pela atmosfera variando de 0,025 a 0,04 . No caso específico deste trabalho, seguiu-se a recomendação de Bastiaanssen et al.(2003), utilizando o valor de 0,025. E $\mathrm{T}_{\mathrm{sw}}$ é a transmissividade da atmosfera que nas condições de transparência calcula-se utilizando a equação (17) de acordo com Allen et al. (2002).

$$
\tau_{s w}=0,75+2 \times 10^{-5} z
$$

Em que $z$ é a altitude em metros de cada pixel da imagem.

$\mathrm{Na}$ terceira etapa foram obtidos índices de vegetação como o Índice de Vegetação por Diferença Normalizada (NDVI), o Índice de Vegetação Ajustado para os efeitos do Solo (SAVI) e o Índice de Área Foliar (IAF).

O (SAVI) é um índice que visa atenuar os efeitos espectrais de "fundo" do solo podendo ser obtido por meio da equação (18) formulada por Huete (1988).

$$
S A V I=\frac{(1+L) \times\left(\rho_{4}-\rho_{3}\right)}{\left(L+\rho_{4}+\rho_{3}\right)}
$$

Sendo L uma variável que oscila entre 0,25 utilizado para vegetação densa, 0,5 utilizado para vegetação intermediária e 1 para vegetação rarefeita. Para este trabalho, utilizou-se 0,5 por se tratar do período de inverno, época em que a vegetação reduz suas atividades metabólicas, por conta dos efeitos da seca, ocorrendo até a perda de folhas.

O (IAF) representa a razão entre todas as folhas contidas em cada pixel pela área do pixel, ou seja, trata-se de um indicador de biomassa de cada pixel da cena, sua estimativa se dá pela equação empírica (19) calibrada por Allen et. al. (2002).

$$
I A F=-\frac{\ln \left(\frac{0,69-S A V I}{0,59}\right)}{0,91}
$$

Na quarta etapa foi obtida a Emissividade da superfície, este é um parâmetro de importância substancial para se obter a temperatura dos constituintes da superfície da Terra, por meio de sensores remotos. Tendo em vista que é necessário inverter a equação de Planck, isso porque na proposta de corpo negro de Planck o mesmo possui emissividade igual a 1 . Como os pixels das imagens não são corpos negros perfeitos, deve-se estimar sua emissividade na propriedade espectral da banda termal do TM Landsat $5\left(\varepsilon_{\mathrm{NB}}\right)$. Neste caso, calcula-se a emissividade, seguindo a proposta de Allen et. al. (2002), a partir das equações (20).

\footnotetext{
${ }^{1}$ Do inglês "background"
} 
No caso dos pixels com IAF $\geq 3$, considera-se $\varepsilon_{\mathrm{NB}}=\varepsilon_{0}=0,98$; para pixels com NDVI $<0$, considera-se $\varepsilon_{\mathrm{NB}}=0,99$ e $\varepsilon_{0}=0,985$

Na quinta e última etapa foi obtida a Temperatura da superfície (Ts) para tanto foi utilizada a radiância espectral da banda termal $L_{\lambda 6}$ e a emissividade das cenas adquiridas na quarta etapa. Desta forma, utilizando a equação (21), obtém-se a temperatura da superfície em (K), posteriormente utilizando a relação $\mathrm{T}^{\circ} \mathrm{C}=\mathrm{TK}-273,5$ converte-se a temperatura de $(\mathrm{K})$ para a temperatura em graus Celsius.

$$
T_{s}=\frac{K_{2}}{\ln \left(\frac{\varepsilon_{N B} K_{1}}{L_{\lambda, 6}}+1\right)}
$$

Em que, $\mathrm{K}_{1}=607,8 \mathrm{Wm}^{-2} \mathrm{sr}^{-1} \mu \mathrm{m}^{-1}$, e $\mathrm{K}_{2}=1261 \mathrm{~K}$, são constantes de calibração da banda termal do TM Landsat 5.

$\mathrm{Na}$ sequência, no intuito de validar os dados obtidos por sensoriamento remoto, foram montadas as tabelas 07,09 e 11 . Nestas tabelas constam os valores dos pixels em que se localiza as estações de controle afim de comparar o valor obtido pelo modelo de sensoriamento remoto (SEBAL) e os valores de referência fornecidos pelas estações de controle. No passo seguinte, com auxilio do software Excel 2007 seguiu-se os procedimentos para o cálculo da variância, desvio padrão e média aritmética dos valores de temperatura das estações e do modelo (SEBAL), no intuito de apresentar o coeficiente de variação percentual destes valores, como destaca as tabelas 08,10 e 12 .

\section{Tabela 07}

Diferença de temperatura entre as estações e o modelo SEBAL - 1985

\begin{tabular}{lccccc}
\hline Estações de controle & Latitude & Longitude & T ${ }^{\circ} \mathbf{C} /$ estação & TO$^{\circ}$ C / SEBAL Diferença ${ }^{\circ} \mathbf{C}$ \\
\hline Itamarandiba/INMET & $17^{\circ} 50^{\prime} \mathrm{s}$ & $42^{\circ} 53^{\prime} \mathrm{w}$ & 19,01 & 17,54 & 1,47 \\
Diamantina/INMET & $18^{\circ} 10^{\prime} \mathrm{s}$ & $43^{\circ} 36^{\prime} \mathrm{w}$ & 23,70 & 21,84 & 1,86 \\
Montes Claros/INMET & $16^{\circ} 41^{\prime} \mathrm{s}$ & $43^{\circ} 50^{\prime} \mathrm{w}$ & 22,00 & 20,12 & 1,88 \\
UNIMONTES & $16^{\circ} 43^{\prime} \mathrm{s}$ & $43^{\circ} 52^{\prime} \mathrm{w}$ & - & - & - \\
Aeroporto SBMK & $16^{\circ} 42^{\prime} \mathrm{s}$ & $43^{\circ} 49^{\prime} \mathrm{w}$ & 24,10 & 22,37 & 1,73 \\
CEPTEC & $16^{\circ} 44^{\prime} \mathrm{s}$ & $43^{\circ} 53^{\prime} \mathrm{w}$ & - & - & - \\
\hline
\end{tabular}




\section{Tabela 08}

Parâmetros estatísticos e coeficiente de variação entre os dados de controle e o modelo SEBAL $-1985$

\section{Coeficiente de}

\begin{tabular}{lcccc} 
Estações de controle & Variância & Desvio padrão & Média aritmética & variação em (\%) \\
\hline Itamarandiba/INMET & 1,08045 & 1,03945 & 18,28 & 5,69 \\
Diamantina/INMET & 1,72980 & 1,31522 & 22,77 & 5,78 \\
Montes Claros/INMET & 1,76720 & 1,32936 & 21,06 & 6,31 \\
UNIMONTES & - & - & - & - \\
Aeroporto SBMK & 1,49645 & 1,22329 & 23,24 & 5,26 \\
CEPTEC & - & - & - & - \\
\hline
\end{tabular}

Tabela 09

Diferença de temperatura entre as estações e o modelo SEBAL - 1995

\begin{tabular}{|c|c|c|c|c|c|}
\hline $\begin{array}{l}\text { Estações de } \\
\text { controle }\end{array}$ & Latitude & Longitude & $\begin{array}{l}\mathrm{T}^{\circ} \mathrm{C} / \\
\text { estação }\end{array}$ & $\begin{array}{l}\text { T' C / } \\
\text { SEBAL }\end{array}$ & iferença ${ }^{\circ} \mathrm{C}$ \\
\hline Itamarandiba/INMET & $17050^{\prime} \mathrm{s}$ & $42^{\circ} 53^{\prime} w$ & 19,70 & 18,33 & 1,37 \\
\hline Diamantina/INMET & $18^{\circ} 10^{\prime} \mathrm{s}$ & $43^{\circ} 36^{\prime} w$ & 19,00 & 18,12 & 0,88 \\
\hline \multicolumn{6}{|l|}{ Montes } \\
\hline Claros/INMET & $16^{\circ} 41^{\prime} \mathrm{s}$ & $43^{\circ} 50^{\prime} \mathrm{w}$ & 23,90 & 20,34 & 3,56 \\
\hline UNIMONTES & $16^{\circ} 43^{\prime} \mathrm{s}$ & $43^{\circ} 52^{\prime} w$ & 0,00 & - & - \\
\hline Aeroporto SBMK & $16^{\circ} 42^{\prime} \mathrm{s}$ & $43^{\circ} 49^{\prime} \mathrm{w}$ & 23,80 & 22,37 & 1,43 \\
\hline CEPTEC & $16^{\circ} 44^{\prime} \mathrm{s}$ & $43^{\circ} 53^{\prime} \mathrm{w}$ & 0,00 & - & - \\
\hline
\end{tabular}

Tabela 10

Parâmetros estatísticos e coeficiente de variação entre os dados de controle e o modelo SEBAL - 1995

Coeficiente

Estações de controle Variância Desvio padrão Média aritmética de variação em (\%)

\begin{tabular}{lcccc}
\hline Itamarandiba/INMET & 0,93845 & 0,96874 & 19,02 & 5,09 \\
Diamantina/INMET & 0,38720 & 0,62225 & 18,56 & 3,35 \\
Montes Claros/INMET & 6,33680 & 2,51730 & 22,12 & 11,38 \\
UNIMONTES & 0,00000 & - & - & - \\
Aeroporto SBMK & 1,02245 & 1,01116 & 23,09 & 4,38 \\
CEPTEC & 0,00000 & - & - & - \\
\hline
\end{tabular}


Tabela 11

Diferença de temperatura entre as estações e o modelo SEBAL - 2010

Estações de controle Latitude Longitude T ${ }^{\circ} \mathrm{C} /$ estação To C / SEBAL $\begin{array}{r}\text { Diferença } \\ \text { oC }\end{array}$

\begin{tabular}{llllll}
\hline Itamarandiba/INMET & $17^{\circ} 50^{\prime} \mathrm{s}$ & $42^{\circ} 53^{\prime} \mathrm{w}$ & 13,10 & 12,70 & 0,40 \\
Diamantina/INMET & $18^{\circ} 10^{\prime} \mathrm{s}$ & $43^{\circ} 36^{\prime} \mathrm{w}$ & 12,10 & 11,71 & 0,39 \\
Montes Claros/INMET & $16^{\circ} 41^{\prime} \mathrm{s}$ & $43^{\circ} 50^{\prime} \mathrm{w}$ & 18,50 & 18,34 & 0,16 \\
UNIMONTES & $16^{\circ} 43^{\prime} \mathrm{s}$ & $43^{\circ} 52^{\prime} \mathrm{w}$ & 19,20 & 18,94 & 0,26 \\
Aeroporto SBMK & $16^{\circ} 42^{\prime} \mathrm{s}$ & $43^{\circ} 49^{\prime} \mathrm{w}$ & 21,30 & 20,07 & 1,23 \\
CEPTEC & $16^{\circ} 44^{\prime} \mathrm{s}$ & $43^{\circ} 53^{\prime} \mathrm{w}$ & 19,00 & 17,98 & 1,02 \\
\hline
\end{tabular}

Tabela 12

Parâmetros estatísticos e coeficiente de variação entre os dados de controle e o modelo SEBAL - 2010

\section{Coeficiente}

Estações de controle Variância Desvio padrão Média aritmética de variação em (\%)

\begin{tabular}{lllll}
\hline Itamarandiba/INMET & 0,08000 & 0,28284 & 12,90 & 2,19 \\
Diamantina/INMET & 0,07605 & 0,27577 & 11,91 & 2,32 \\
Montes Claros/INMET & 0,01280 & 0,11314 & 18,42 & 0,61 \\
UNIMONTES & 0,03380 & 0,18384 & 19,07 & 0,96 \\
Aeroporto SBMK & 0,75645 & 0,86974 & 20,69 & 4,20 \\
CEPTEC & 0,52020 & 0,72124 & 18,49 & 3,90 \\
\hline
\end{tabular}

Como destacado nas tabelas 07, 09 e 11, a menor diferença entre a temperatura da estação e a temperatura do SEBAL foi de apenas $0,16{ }^{\circ} \mathrm{C}$, revelando um coeficiente de variação de $0,61 \%$ em 2010. A maior diferença de temperatura ocorreu para a mesma estação, a estação de Montes Claros, sendo 3,56 ${ }^{\circ} \mathrm{C}$ de diferença, implicando em uma variação de $11,38 \%$ no ano de 1995.

Fato que destaca uma correlação entre os dados obtidos por sensoriamento remoto (SEBAL) e os dados das estações de controle variando entre $88,62 \%$ e $99,84 \%$ de semelhança.

\section{RESULTADOS}

Para o ano de 1985, as áreas de Cerrado somavam 119,50 $\mathrm{km}^{2}$, de acordo com a Figura 04. A maior concentração dos pixels, da área classificada como Cerrado e afins, oscilou entre 17,63 e $20,38^{\circ} \mathrm{C}$, cuja maior concentração, aproximadamente, 7900 pixels, isto é, $95,20 \%$ da área apresentava valores de temperatura entre 17,63 e $19,91^{\circ} \mathrm{C}$.

No que se refere ao albedo da superfície, os valores de reflexão para as áreas de Cerrado ficaram entre 6,26 e 15,58\%, com a maior concentração entre 6,26 e 10,29\% de reflexão. Gomes (2009) encontrou valores para o albedo de superfície para áreas de cerrado e eucalipto oscilando entre 9 e 13\%. Vale salientar que este autor trabalhou com imagens de várias estações do ano nas condições do Município de Santa Rita do Passa Quatro - SP.

A Floresta Tropical Caducifólia (FTC) ocupava 129,80 km² de área, em 1985. A distribuição dos pixels por classe de temperatura se deu de forma relativamente equiparada, como relata a 
Figura 04, com duas exceções, a classe de temperatura entre 19,09 e $19,54{ }^{\circ} \mathrm{C}$, a qual detém a maior concentração de pixels, e a classe de temperatura entre 20,39 e $22,37^{\circ} \mathrm{C}$, que marca uma pequena porção em área de (FTC) neste intervalo de temperatura. Como destaca a Figura 05, a maior concentração de pixels entre as classes de reflexão para a (FTC) ocorreu entre os intervalos de 6,26 a 11,75\%, representando cerca de $95,34 \%$ da área de (FTC), restando menos de $5 \%$ de área com outras classes de reflexão.

A Floresta Tropical Subcaducifólia (FTS) possuía, em 1985, 18,40 km² de área. Desse montante $86,09 \%$ apresentava oscilações de temperatura entre 17,63 e $19,91{ }^{\circ} \mathrm{C}$. No que diz respeito ao albedo de superfície da (FTS), a maior concentração de área apresentou poder de reflexão entre 10,37 e $13,40 \%$.

Do ponto de vista da pastagem, sua área total, em 1985, era de 252,62 km², cuja concentração de área por classe de temperatura, revelada pela Figura 04, indica aproximadamente $88,35 \%$ da área com temperaturas oscilando entre 19,09 e $20,38{ }^{\circ} \mathrm{C}$. Para 0 albedo da superfície da área de pastagem ocorreu maior concentração de pixels, no ano de 1985 , entre os intervalos de reflexão de 10,30 e 15,58\%. De forma que a maior concentração de áreas de pastagem ficou entre 11,76 e 13,40\% de reflexão.

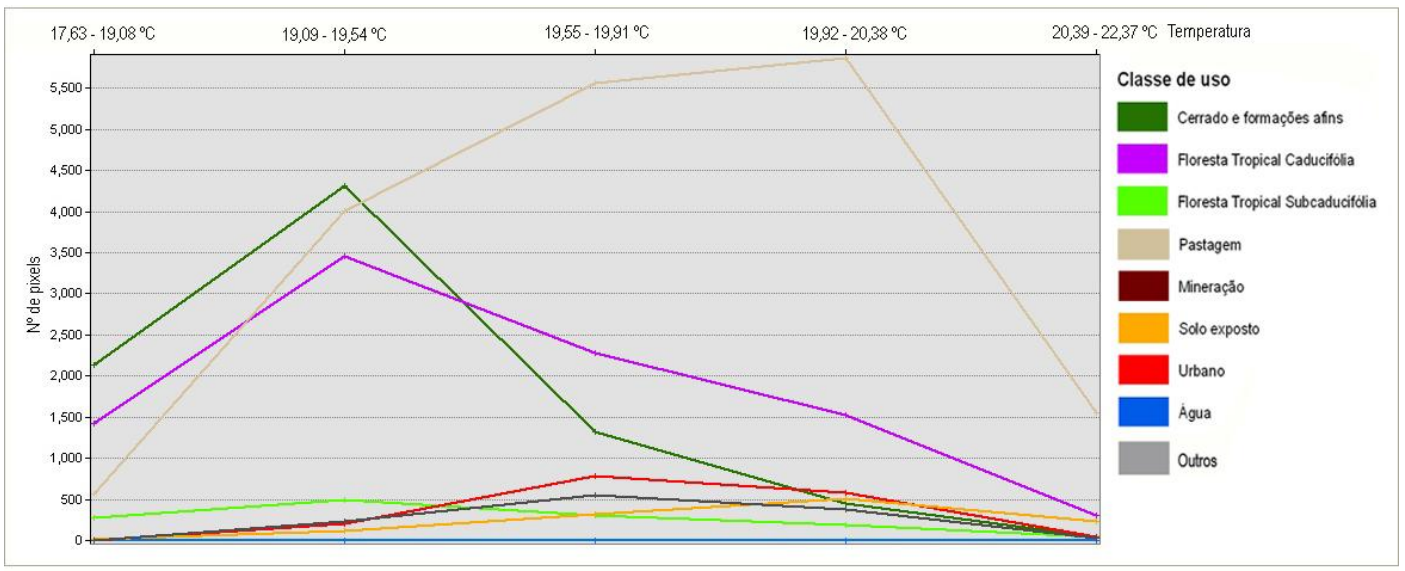

Figura 04 - Sistemas de uso da terra por classe de temperatura na bacia do Rio Vieira/1985 - 09h 26mim

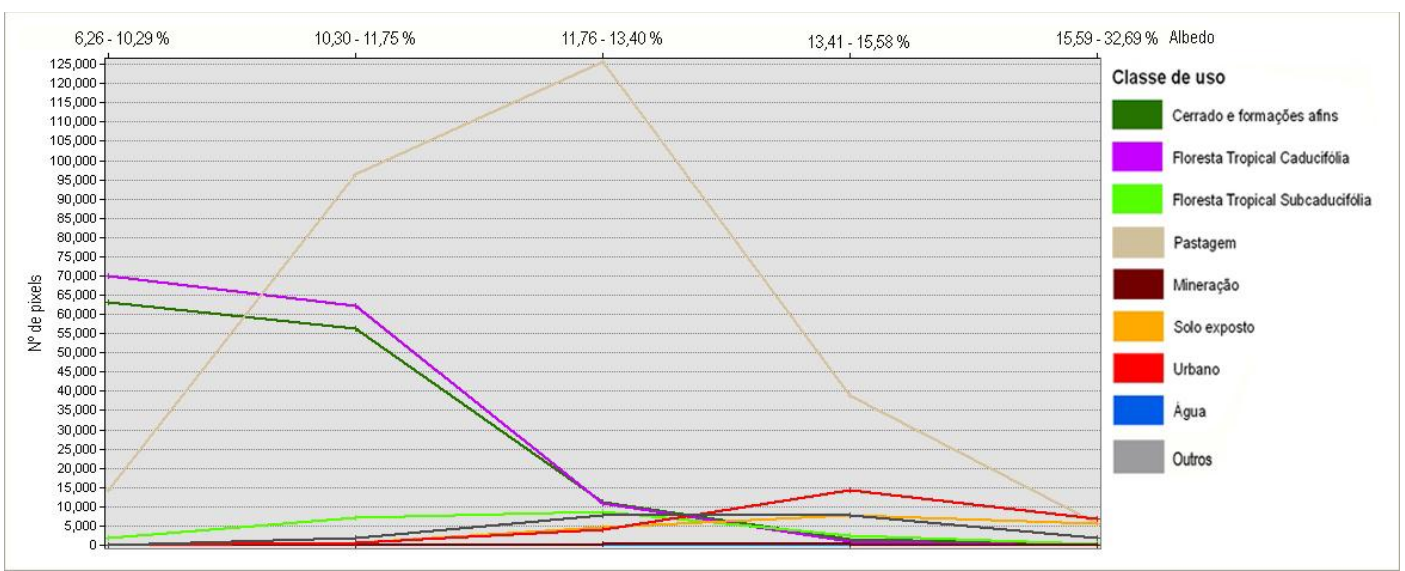

Figura 05 - Sistemas de uso da terra por classe de albedo na bacia do Rio Vieira/1985 - 09h 26mim

As áreas destinadas à extração de calcário para a fabricação de cimento em 1985, classificadas como áreas de mineração, apresentaram valores de temperatura oscilando entre 19,52 e $21,66{ }^{\circ} \mathrm{C}$, com a maior concentração das terras apresentando valores de temperatura entre 20,00 e $20,83{ }^{\circ} \mathrm{C}$. 
Quanto ao albedo a mineração apresentou valores entre 8,70 e 17,90\% de reflexão, cuja área de maior concentração de pixels apresentou valores entre 11,98 e 14,27\%.

As áreas de solo exposto apresentaram, conforme a Figura 04, valores de temperatura entre 19,09 e $22,37^{\circ} \mathrm{C}$. Cerca de $68,37 \%$ do total da área de solo exposto apresentou classes de temperatura entre 19,55 e $20,38^{\circ} \mathrm{C}$. Quanto ao albedo de superfície a classe de solo exposto apresentou poder de reflexão concentrado, em sua maior parte, entre 13,41 e $32,69 \%$.

A área urbana edificada da cidade de Montes Claros, no ano de 1985 , era de $22,74 \mathrm{~km}^{2}$. A distribuição desta área, para o ano considerado, apresentou cerca de $91,82 \%$ de sua área, com intervalos de temperatura de 19,55 e $20,38^{\circ} \mathrm{C}$. No que concerne ao albedo da superfície, a área urbana apresentou cerca de $59,37 \%$ de pixels, com poder de reflexão entre 13,41 e $32,69 \%$.

No tocante à classe denominada de (Água), esta representa, basicamente, as lagoas e lagos da bacia, tendo em vista que os canais concentrados, em sua maioria, são estreitos de mais para aparecer nas imagens. Desta maneira, a temperatura deste ambiente oscilou, no ano de 1985 , entre 18,34 a $19,52{ }^{\circ} \mathrm{C}$, enquanto o poder de reflexão, ou seja, o albedo, apresentou valores da ordem de 6,26 a 10,29\%, valores estes bem similares aos encontrados por Menezes (2006) e Gomes (2009).

A classe de uso da terra denominada de outros, como discutido no item 2.1, assemelha-se muito à resposta espectral da classe de pastagem. Desta forma, já era de se esperar a tendência de comportamento, do ponto de vista da temperatura e do albedo, de forma similar à classe de pastagem. Para o ano de 1985, a classe "outros" apresentou a maior concentração de área nas classes de temperatura entre 19,55 e 20,38 ${ }^{\circ} \mathrm{C}$. Esta semelhança também foi corroborada no agrupamento do maior número de pixel, classificados como "outros", como destaca a Figura 05, nos intervalos de reflexão de maior ocorrência da área de pastagem, isto é, 11,76 e $13,40 \%$.

Do ano de 1985 para o ano de 1995, ocorreu uma perda de 18,87 km² de área de Cerrado, de forma que para o ano de 1995 a área de Cerrado e afins somava 100,63 km². As classes de uso da terra que avançaram sobre o Cerrado foram: pastagem, urbano, solo exposto, eucalipto e outros, dados os motivos apresentados no item 3.2.

No que se refere às temperaturas da área de Cerrado e afins para o ano de 1995, como descreve a Figura 06 , os valores oscilaram entre 18,57 e $20,84{ }^{\circ} \mathrm{C}$. Do total da área de Cerrado, aproximadamente $96 \%$ apresentou temperaturas entre 18,57 e $20,37^{\circ} \mathrm{C}$. Do ponto de vista quantitativo, ocorreu um aumento em relação ao ano de 1985, entre a menor temperatura e a maior, para a área de Cerrado, da ordem de 0,13 e 0,59 ${ }^{\circ} \mathrm{C}$, respectivamente.

Difícil dizer se essa variação se deu em função da redução da área de cerrado, tendo em vista que, de forma geral, a bacia do Rio Vieira apresentou valores de temperatura mais elevados para o ano de 1995 em relação ao ano de 1985.

É possível notar, a partir da análise das Figuras 04 e 06, que, das classes de uso da terra responsáveis pela substituição do Cerrado, apenas as áreas de eucalipto e pastagem apresentaram pixels com temperaturas equivalentes ou inferiores a maior tendência de temperatura por área de Cerrado.

Cerca de 97,79\%, de acordo com a Figura 06, da área de eucalipto agrupou valores de temperatura entre 18,57 e $19,44{ }^{\circ} \mathrm{C}$. Classe de temperatura, esta, que se encontra ligeiramente inferior à linha de tendência do Cerrado, para o ano de 1995, que é de 19,45 a $19,91^{\circ} \mathrm{C}$.

Os pixels classificados como pastagem e agrupados entre os valores de temperatura de 18,57 e 19,44 ${ }^{\circ} \mathrm{C}$ revelam duas situações: a primeira, de que as áreas de pastagem tenderam a responder ao aumento de temperatura do ambiente, para o horário mapeado, e estavam mais quentes em 1995 do que dez anos antes, no ano de 1985; segunda, que as áreas de Cerrado que foram substituídas pela pastagem tenderam a acompanhar este movimento. 
Essa argumentação pode ser comprovada pela seguinte análise: em 1985, como revela a Figura 04, a concentração de pixels entre os valores de temperatura de 17,63 e $19,54{ }^{\circ} \mathrm{C}$ era de aproximadamente 4500 pixels, isso era equivalente a $64,80 \mathrm{~km}^{2}$ de área, a qual estava distribuída entre duas colunas do eixo das ordenadas. Para o ano de 1995, entretanto, a classe de temperatura compreendida entre os intervalos de 18,57 e 19,44 praticamente abarca todo o intervalo de temperatura, referente ao ano de 1985, porém, com apenas 400 pixels, ou 5,76 $\mathrm{km}^{2}$ de área. Ou seja, as áreas de pastagem para o ano de 1995 tenderam a temperaturas mais elevadas do que dez anos antes.

A expansão urbana mais as áreas de solo exposto contribuíram para a substituição das áreas de Cerrado. A área urbana de forma direta, isto é, ocorreu retirada de Cerrado para a implantação de área urbana, ou pelo menos para a abertura de ruas e avenidas futuras. A área de solo exposto substituiu o Cerrado de forma indireta, como resultado do desmatamento acarretado pela implantação de pastos ou de equipamentos urbanos.

Do ponto de vista térmico, as duas áreas apresentaram concentrações de pixels acima da tendência do Cerrado, como descreve a Figura 06, de forma que a substituição do Cerrado por estas classes de uso da terra implicaram em concentrações de áreas com temperatura mais elevadas, no horário e no ano mapeado.

A classe "outros" tendeu, no horário mapeado, ao comportamento térmico da área de maior concentração da pastagem, apresentando, também, temperaturas mais elevadas do que a maioria da área de Cerrado.

É possível dividir as classes que substituíram o cerrado em três tipos: densamente arborizada (eucalipto), pouco arborizada (pastagem, outros) e não arborizada (solo exposto, área urbana edificada). Desses usos da terra, apenas a área densamente arborizada apresentou valores de temperatura, por área significativa, inferior ou igual a da antiga cobertura, enquanto as demais tenderam, no horário mapeado, a temperaturas mais elevadas.

No que se refere à área de (FTC), do ano de 1985 para o ano de 1995, a mesma apresentou aumento de $20,66 \mathrm{~km}^{2}$ de área, por motivos explicitados no tópico 3.1. Do ponto de vista da temperatura, o ano de 1985 apresentou valores mínimos e máximos entre 18,33 e $22,37{ }^{\circ} \mathrm{C}$, enquanto que para o ano de 1995 estes valores foram de 18,50 e 22,60 ${ }^{\circ} \mathrm{C}$. De forma que a temperatura média da área de (FTC) para o ano de 1985 era de $19,58{ }^{\circ} \mathrm{C}$ e para o ano de 1995 era de $19,91^{\circ} \mathrm{C}$. Com efeito, para o ano de 1995, 82,31\% das terras cobertas por (FTC) apresentaram temperaturas oscilando entre 18,57 e $20,37^{\circ} \mathrm{C}$, fato que revela uma tendência das áreas de (FTC) acompanharem a linha das menores temperaturas, já que o ano de 1995 apresentou valores mais elevados de temperatura para o ambiente analisado, e a área de floresta tendeu as temperaturas mais amenas da Figura 06.

As áreas de (FTS) apresentaram aumento de 0,68 km², do ano de 1985 para o ano de 1995 . De forma semelhante a (FTC) a (FTS) tendeu as menores temperaturas, já que $93,91 \%$ de sua área apresentou temperaturas entre 18,57 e $20,37{ }^{\circ} \mathrm{C}$, restando apenas $6,09 \%$ de área com as temperaturas mais elevadas.

É importante relatar que a área de pasto da bacia do Rio Vieira apresentou redução de 26,99 $\mathrm{km}^{2}$, muito em função da recuperação das áreas de (FTC) e, principalmente, em função do aumento das classes urbanas e de solo exposto, as quais somadas foram responsáveis por $67,36 \%$ da redução da área de pastagem. Do ponto de vista da temperatura, os valores mínimos e máximos, entre os anos de 1985 e 1995, apresentaram uma diferença de 0,25 ${ }^{\circ} \mathrm{C}$ para a mínima e de $0,01^{\circ} \mathrm{C}$ para a máxima.

É preciso observar, contudo, que para o ano de 1995, para o horário mapeado, a área de pastagem, como explicita a Figura 06, apresentou uma concentração maior de pixels, cerca de 11400 ou $72,12 \%$ da área, para ser mais exato, entre intervalos de temperatura de 19,92 e $22,61{ }^{\circ} \mathrm{C}$, fato que justificou uma temperatura média para este ambiente em 1995, de $20,22^{\circ} \mathrm{C}$, representando um aumento de $0,36^{\circ} \mathrm{C}$ para a temperatura média do ano de 1985. Essa análise, contudo, não permite inferir se a elevação da temperatura deste ambiente 
ocorreu em função da redução de sua área, tendo em vista que o ano em questão apresentou temperaturas mais elevadas em relação aos demais anos mapeados.

É possível inferir, de acordo com esses dados, uma tendência deste sistema de uso da terra em responder, mais rapidamente, a alterações térmicas do ambiente. Isto é, como o ano de 1995 apresentou, no horário mapeado, temperaturas mais elevadas para a bacia, a área de pastagem respondeu, com cerca de $95,09 \%$ de sua área, a este aumento de temperatura.

Essa análise, por sua vez, nos permite fazer outra inferência: se este ambiente tende a responder a mudanças rápidas de temperatura, possivelmente, no período noturno, quando ocorre fluxo de calor do solo para as camadas atmosféricas mais próximas da superfície, esta área tende a perder a energia térmica armazenada durante 0 fotoperíodo e, consequentemente, resfriar-se no período noturno. Isso comparado com sistemas de uso da terra que apresentam um padrão mais estável de liberação de energia térmica para o meio, como as áreas vegetadas, por exemplo.

No que tange à classe de uso urbano e à classe de solo exposto, é possível identificar uma relação entre aumento da área e uma padronização dos intervalos de temperatura. No exemplo das áreas urbanas $88,75 \%$, para o ano de 1985 , apresentava temperaturas entre 19,55 e $20,38{ }^{\circ} \mathrm{C}$. No ano de 1995 , ocorreu um aumento da ordem de $15,97 \mathrm{~km}^{2}$, isto é, um aumento de $70,23 \%$ de área. Os intervalos de temperatura, todavia, ficaram entre 19,92 e $20,84{ }^{\circ} \mathrm{C}$, representando $85,56 \%$ da área urbana, para o ano de 1995 . Ou seja, embora o aumento, em área superficial, tenha sido considerável a concentração dos intervalos de temperatura apresentou elevação de apenas 0,37 e $0,46{ }^{\circ} \mathrm{C}$, respectivamente, indicando muito mais a resposta ao aumento de temperatura do ano mapeado em relação ao seu antecessor do que um aumento de temperatura em função da expansão da área urbana.

A mesma análise cabe às áreas classificadas como solo exposto, isto é, embora o aumento, em área superficial, da Figura 06 para a Figura 05, tenha sido significativo para a classe de uso da terra, os intervalos de temperatura foram muito semelhantes.

Do ponto de vista do albedo de superfície das classes de uso da terra do ano de 1995 em relação ao ano de 1985, alguns usos indicam comportamento semelhante, como o caso das áreas de Cerrado e (FTC) que tendem apresentar áreas com poder de reflexão entre 6 e 14,5\%, como indica as Figuras 05, 07 e 35. Destaque, também, para as áreas de eucalipto e (FTS), as quais, do ponto de vista da reflexão, apresentaram semelhanças entre si e entre os intervalos dos anos mapeados, destacando um padrão de reflexão entre 6,17 e $14,80 \%$ de reflexão.

As áreas de pastagem, para os anos de1985 e 1995, indicaram uma relação de reflexão compreendida entre intervalos de 6,16 e $16 \%$. Já as terras cujo uso indicava urbano e solo em exposição apresentaram padrões de reflexão, conforme as Figuras 05, 07 e 09 indicam.

É importante lembrar que a resposta do albedo depende e sofre influência de fatores variados, como o tipo e a característica da superfície, a ocorrência de ventos fortes, a presença de áreas irrigadas, etc. Contudo, para os anos de 1985 e 1995, a resposta do albedo indicou mais de $70 \%$ das áreas urbanas e de solo em exposição, com os intervalos de reflexão supramencionados. 


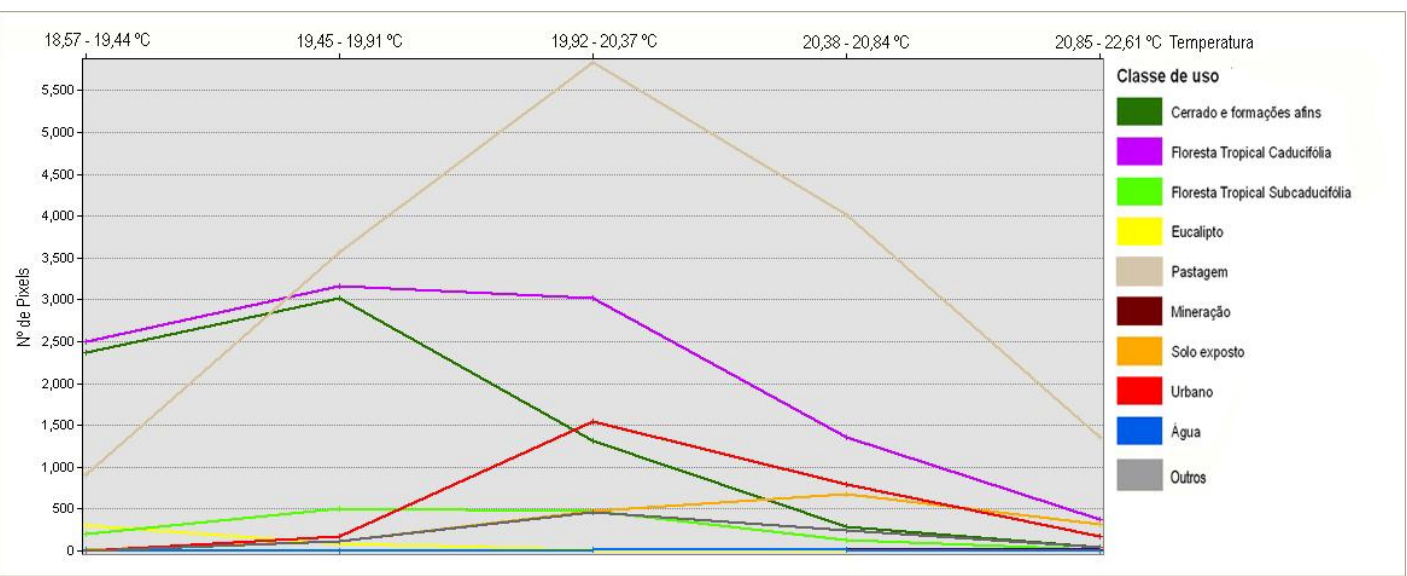

Figura 06 - sistemas de uso da terra por classe de temperatura na bacia do Rio Vieira/1995 - 08h58min

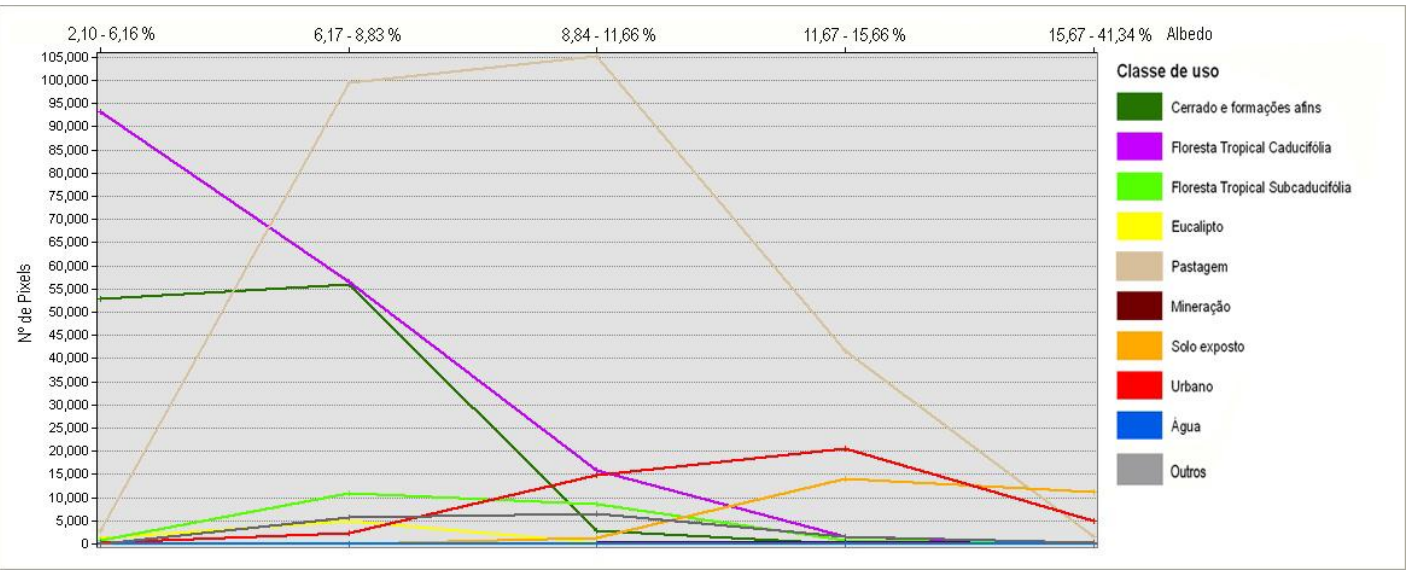

Figura 07 - sistemas de uso da terra por classe de albedo na bacia do Rio Vieira/1995 - 08h58min

O ano de 2010 apresentou as temperaturas mais amenas. Com efeito, do ano de 1995 para o ano de 2010, a diferença da temperatura mínima aponta uma queda de $1,91^{\circ} \mathrm{C}$ para a mínima e de $0,23^{\circ} \mathrm{C}$ para a máxima. Já para o ano de 1985 , esta diferença marca uma queda $0,97^{\circ} \mathrm{C}$ para a mínima e um aumento de 0,01 ํ para máxima.

Um ponto a ser mencionado diz respeito à cobertura vegetal do ano de 2010 . Para esse ano foi verificado um acréscimo nas áreas vegetadas da bacia do Rio Vieira em relação ao ano de 1985 de 9,47\%, ou 54,79 km² de área. Para o ano de 1995 foi identificado um aumento de $8,99 \%$, isto é, $52,01 \mathrm{~km}^{2}$ de áreas vegetadas. Esse aumento das áreas vegetadas ficou basicamente por conta das áreas de Cerrado, (FTC), (FTS) que juntas representavam 55,71\% das terras da bacia.

Do ponto de vista da relação entre uso da terra e temperatura de superfície, a Figura 08 sanciona a argumentação anterior de que as áreas de cerrado, (FTC) e (FTS) tendem as menores temperaturas. Como exemplo, pode-se citar o fato de que $86,71 \%$ das áreas destes usos da terra apresentaram temperaturas entre 16,66 e $18,61^{\circ} \mathrm{C}$, ou seja, acompanhando os padrões das menores temperaturas para o ano de 2010.

Outro ponto que merece ser destacado nesta análise é o fato de que a bacia apresentou dois domínios bem marcados, um de ocupação natural, o qual compreende as classes de vegetação natural e água da bacia, e as áreas de ocupação humana de uso intenso.

Do ponto de vista da temperatura, esses ambientes também podem ser agrupados nestes dois domínios, tendo em vista que pela análise da Figura 08 percebe-se nitidamente que os padrões de uso da terra como Cerrado, (FTC), (FTS) e as áreas de eucalipto tendem a se 
movimentar no sentido das menores temperaturas. De outro modo, as áreas de pastagem, solo exposto, outros e urbano movimentaram-se, nos anos e horários mapeados, no sentido das temperaturas mais elevadas dos gráficos.

A representação em área das ditas classes antrópicas, cujas classes de temperatura oscilavam entre 18,15 e $22,38{ }^{\circ} \mathrm{C}$ era de $89,72 \%$, com exceção da área de eucalipto, a qual embora seja de uso antrópico apresentou tendências semelhantes às áreas de vegetação natural, principalmente quando comparadas com as áreas de (FTS).

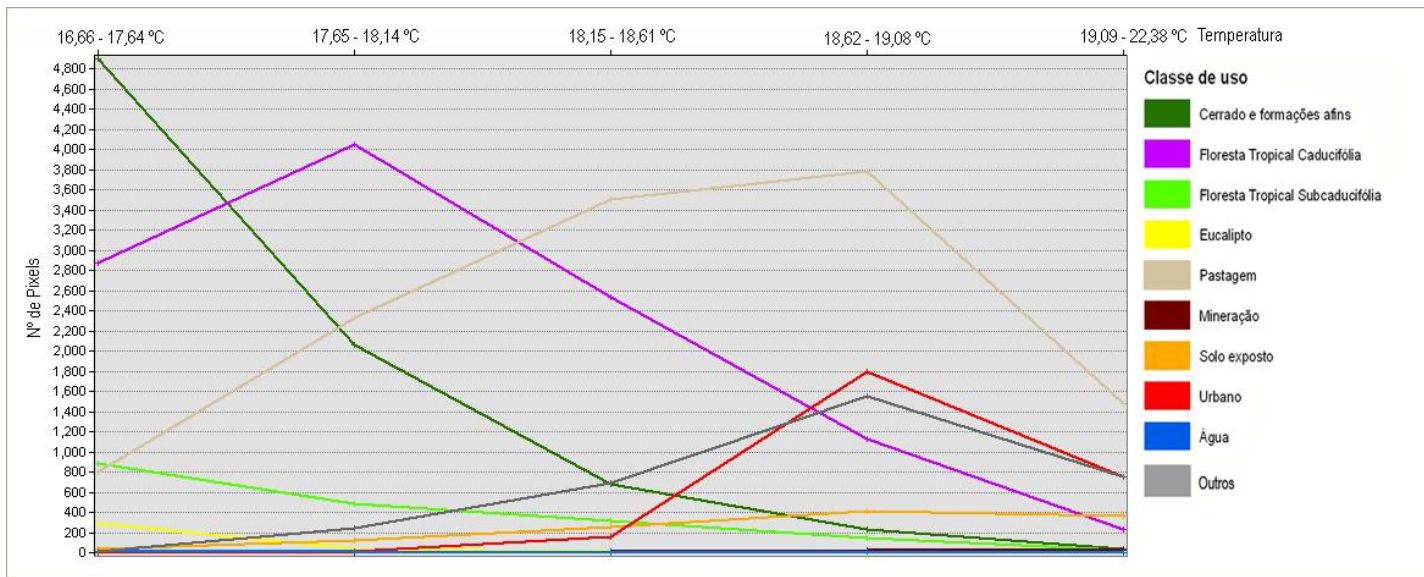

Figura 08 - sistemas de uso da terra por classe de temperatura na bacia do Rio Vieira/2010 - 09h46min

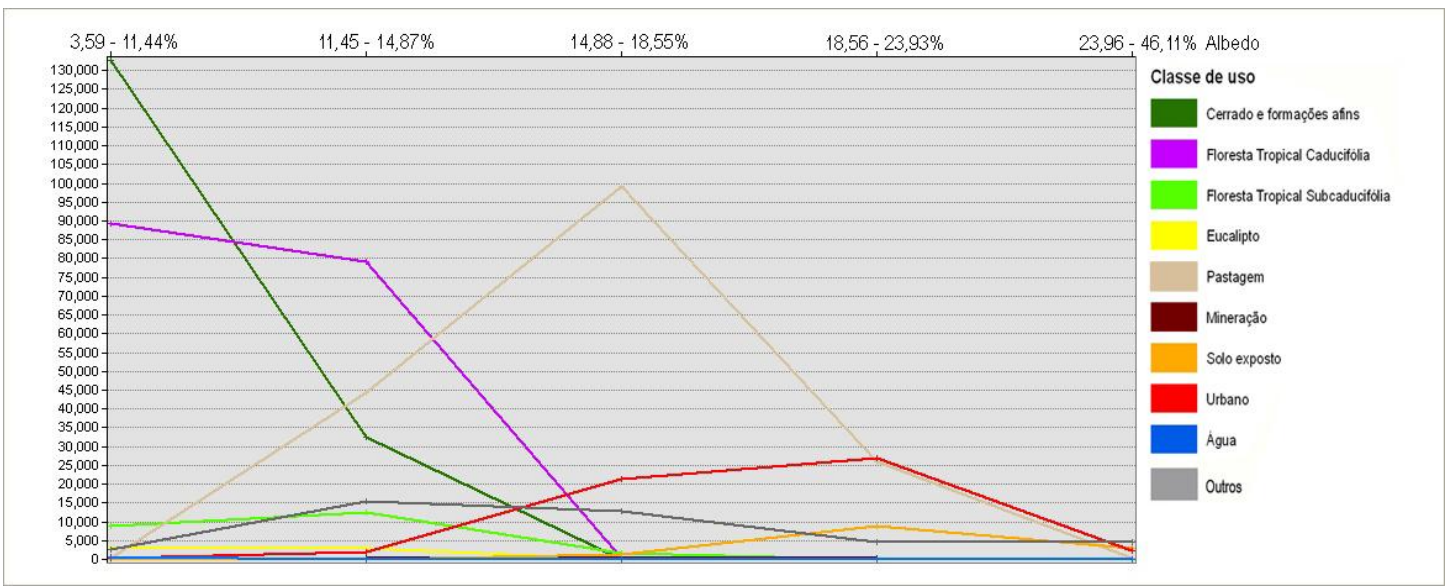

Figura 09 - sistemas de uso da terra por classe de albedo na bacia do Rio Vieira/2010 - 09h46min

Sobre o albedo de superfície a Figura 09 contribui para a validação da argumentação das linhas de tendência de reflexão, nos horários mapeados, sobretudo no caso das áreas de Cerrado e (FTC) em que basicamente não ocorre reflexão, nestas áreas, acima de $14,89 \%$ em todos os anos mapeados. De forma semelhante os eucaliptais também apresentaram coerência, entre os intervalos de reflexão e os anos mapeados mantendo sua oscilação entre 3,59 e $14,87 \%$. Resultado parecido com os da (FTS) marcando um padrão de reflexão destes sistemas de uso da terra para os horários compreendidos entre $8 \mathrm{~h} 58 \mathrm{mim}$ e $9 \mathrm{~h} 46 \mathrm{mim}$.

As pastagens apresentaram oscilações de reflexão entre 2,26 a 32,69\% entre os anos mapeados. Dentre esses intervalos de reflexão, ao longo de todos os anos mapeados, conforme as Figuras 05, 07 e 09, os intervalos de maior concentração de pixels deste sistema de uso da terra foram de 6,26 a $15,58 \%$ de reflexão.

Os sistemas de uso urbano e de solo exposto também mantiveram uma semelhança entre os intervalos de reflexão ao longo dos anos, como destaca a Figura 09 em relação as Figuras 05 e 07. 
A classe de uso da terra denominada de outros tendeu a responder, entre os anos mapeados, aos intervalos de temperatura da área de pastagem, tanto no que diz respeito à temperatura de superfície quanto ao seu poder de reflexão.

De forma direta, pode se perceber duas linhas te tendência: uma referente às áreas de Cerrado, (FTC), (FTS) e de eucalipto, tendendo sempre a concentrar, em maior proporção, suas áreas nos intervalos de temperaturas mais amenos. E as áreas de Pastagem, Mineração, Solo Exposto, Urbano e Outros, concentrando, ao longo dos anos mapeados, áreas em intervalos de temperatura mais elevados.

Do ponto de vista analítico, ocorreu aumento de temperatura, com exceção das áreas plantadas de eucalipto. Nos casos em que a vegetação natural foi substituída por espaços antrópicos e, de forma contrária, ocorreu diminuição dos valores de temperatura no passo em que as áreas antropizadas foram substituídas pela vegetação natural recuperada.

A exemplo dessa realidade cabe analisar as áreas recuperadas dentro do limite do Parque Estadual da Lapa Grande entre os anos de 1985 a 2010, cuja área vegetada se recuperou e, consequentemente, os intervalos de temperatura tenderam aos menores intervalos ao longo de sua recuperação.

Outro exemplo remete a expansão da área urbana que no ano de 2010 praticamente não apresenta intervalos de temperatura menores que $18{ }^{\circ} \mathrm{C}$, exceto para as poucas áreas vegetadas e as áreas de reservatórios.

Diante desses resultados, pode se avaliar que ocorreu uma movimentação dinâmica entre o uso da terra e a temperatura e o albedo de superfície da bacia do Rio Vieira, nos anos e horários mapeados. No contexto geral, quando a ocupação dos ambientes se deu de forma antrópica, as temperaturas tenderam a elevar-se, com exceção das áreas de eucalipto, que ao contrário tendeu a temperaturas mais amenas que espaços naturais nativos, como as áreas de Cerrado por exemplo.

É importante frisar que os eucaliptais da bacia encontram-se locados sobre superfícies tabulares reelaboradas, as quais funcionam como importantes unidades de recarga hídrica para os rios da bacia. Desta forma, as temperaturas mais amenas nestas áreas estão ligadas à presença de água na vegetação que implicou na elevação dos valores de emissividade de superfície, contribuindo, por sua vez, para a diminuição da temperatura nesses ambientes. Fato que não deixa de indicar uma alteração no ambiente, tendo em vista que naturalmente essas áreas eram cobertas pelo Cerrado e que no período de inverno não apresenta a mesma disponibilidade hídrica em seus espécimes. Como consequência, as lagoas e lagos, bem como os córregos e rios, das proximidades desse ambiente possivelmente estão submetidos a dinâmicas diferentes das naturais.

\section{CONSIDERAÇÕES FINAIS}

Do ponto de vista operacional, o tempo de execução da metodologia descrita no tópico 2, desde a aquisição dos produtos orbitais até a validação dos mapeamentos, foi relativamente curto. Fato que merece destaque, sobretudo, porque permitiu a elaboração de uma vasta gama de informações temporais da bacia do Rio Vieira. Como exemplo, pode-se citar a inversão dos tipos de uso cujos valores revelam uma recuperação de $54,79 \mathrm{~km}^{2}$ de vegetação natural em 25 anos.

Com efeito, a diferença entre os domínios naturais e antrópicos da bacia em 1985 era de 43,33 $\mathrm{km}^{2}$ a mais de áreas antrópicas. Já para o ano de 2010 , essa diferença era de $67,25 \mathrm{~km}^{2} \mathrm{a}$ mais de áreas naturais. Destaque deve ser dado para as áreas de Cerrado, no ano de 2010, com uma recuperação de $32,30 \%$ em relação ao ano de 1985 . Para as áreas de florestas, ocorreu um aumento percentual de 30,95\% de área em relação ao ano de 1985.

Como resultado da recuperação das áreas vegetadas, ocorreu uma redução da ordem de $39,98 \%$ da área de pastagem e de $8,12 \%$ de solo exposto em relação aos dados de 1985 . A redução da área de pastagem destaca, de forma implícita, a saída da população das áreas rurais, tanto das áreas da bacia como de outras áreas da região do Norte de Minas, propiciada pela grande atração populacional, ocorrida por volta da década de 1970, para a cidade de Montes Claros.

Do ponto de vista do mapeamento termal, o coeficiente de variação apontou uma correlação entre os dados de temperatura obtidos pelo modelo SEBAL e os dados de temperatura do ar, medidos a aproximadamente $1,5 \mathrm{~m}$ do solo, variando de 0,61 e $11,38 \%$ e uma correlação geral 
em $r^{2}=0,961$. Essa validação se mostrou altamente eficiente, tendo em vista que os dados do TM Landsat 5 são coletados a uma altitude de $705 \mathrm{~km}$ altura.

A validação estatística permite concluir que a estimativa da emissividade infravermelha obtida pelo presente algoritmo satisfez a necessidade de obtenção da modelagem térmica da bacia do Rio Vieira a partir dos canais espectrais do sensor TM Landsat 5.

No que diz respeito à relação estabelecida entre os dados de temperatura e albedo de superfície entre os anos e horários mapeados, a resposta do ambiente, quando da substituição da vegetação natural, implicou em elevação dos valores de temperatura de superfície. De forma contrária, quando da recuperação das áreas vegetadas a superfície tendeu, no horário mapeado, a temperaturas mais amenas dos gráficos.

Pode se especular que a presença da vegetação natural implica em maior umidade da superfície e até mesmo a diferença do dossel da vegetação, imposta pelos diferentes portes da mesma, pode acarretar alterações nos dados de sensoriamento remoto.

Desta forma, é importante que estudos posteriores analisem o comportamento sazonal da emissividade de superfície em relação a diferentes épocas do ano, e aos diferentes dados de sensores remotos em relação à presença de diferentes usos da terra. Tendo em vista a necessidade de apontar conclusões concretas para a relação entre heterogeneidade e umidade da superfície e sua relação entre a temperatura e o albedo da mesma, tendo em vista a possibilidade de informações relativo ao comportamento térmico dos usos da terra para uma maior e melhor gerencia dos ambientes naturais e humanos da superfície terrestre.

\section{Referências}

.ALLEN, R. G., TASUMI, M. AND TREZZA, R. SEBAL (Surface Energy Balance Algorithms for Land) Advanced Training and Users Manual - Idaho Implementation, version 1.0, 97 p., 2002.

.BASTIAANSSEN, W. G. M. Regionalization of surface flux densities and moisture indicators in composite terrain. Ph.D. Thesis, Wageningen Agricultural University, Wageningen, Netherlands, 237p., 1995.

.CHAVEZ, P.S., JR. 1988. An improved dark-object subtraction technique for atmospheric scattering correction of multispectral data. Remote Sensing of Environment 24:459-479.

.DUFFIE, J.A., BECKMAN, W.A., 1980. Solar Engineering of Thermal Process, 1ed. John Wiley and Sons, $\mathbf{N Y}$.

.DUFFIE, J.A., BECKMAN, W.A., 1991. Solar Engineering of Thermal Process, 2ed. John Wiley and Sons, NY.

.EFEITO estufa e a convenção sobre mudança do clima. [Brasília, DF]: Ministério da Ciência e Tecnologia: BNDES, 1999. 38 p.

.ENVI 4.7., Decision Tree Classification:Tutorial, 2010. p.7

.GLERIANI, J. M., ANTUNES. M. A. H., EPIPHANIO J. C. N. COEFICIENTES DA TRANSFORMAÇÃO ESPECTRAL TASSELED CAP PARA UMA CENA COM PREDOMÍNIO DE LATOSSOLO ROXO In: Simpósio Brasileiro de Sensoriamento Remoto (SBSR) 05-10 abril 2003, Belo Horizonte. Anais, INPE,p. 101107.

.GOMES, H.B.; Balanço de Radiação e energia em Áreas de cultivo de cana-de-açúcar e cerrado no estado de São Paulo mediante imagens orbitais. Universidade Federal de Campina Grande, 2009.

Tese de doutorado em Meteorologia, p. 108.

. HEYMANN, Y. Corine land cover technical guide. Colaboração de Chris Steenmans, Guy Croisille e Michel Bossard. Luxembourg: European Commission, 1994. $136 \mathrm{p}$

.HUETE, A.R., A soil-adjusted vegetation index (SAVI). Remote Sensing Environ. 1988, p. 295 309.

.IBGE, Instituto Brasileiro de Geografia e Estatística. Censo 2010, disponível em: http/www.ibge.gov.br, acessado em: 21/02/2011.

.IBGE. Manual técnico de uso da terra. Manuais técnicos em geociências, Rio de Janeiro, 2006. ISSN 0103-9598. $91 \mathrm{p}$.

MARKHAM, B. L., BARKER, J. L. Landsat MSS and TM post-calibration dynamic ranges, exoatmospheric reflectances and at-satellite temperatures, EOSAT Landsat Technical Notes, $v$. 1, p. 3-8, 1986.

.MENEZES, S. J. M. da Costa. Evapotranspiração regional utilizando o SEBAL em condições de relevo montanhoso. Universidade Federal de Viçosa. Dissertação de mestrado em engenharia agrícola. Viçosa, 2006. p.84.

.SMITH, J.A.; LIN, T.L.; RANSON, K. The lambertian assumption and Landsat data. . Photogrammetric Engineering and Remote Sensing. v.46, n.9, p1183-1189, 1980. 